http://jmscr.igmpublication.org/home/ ISSN (e)-2347-176x ISSN (p) 2455-0450

crossref DOI: https://dx.doi.org/10.18535/jmscr/v7i10.55

\author{
Journal Of Medical Science And Clinical Research \\ IGM Publication \\ An official Publication of IGM Publication
}

\title{
Unusual Presentation of Appendicitis and a viewing Eosinophilia in Sub acute Appendicitis
}

\author{
Authors
}

Dr Gayathri M. N, Dr Pavan Kumar M.

Department of Pathology, Mysore Medical College and Research Institute, Mysuru, Karnataka, India *Corresponding Author

\section{Dr Apoorva N}

Department of Pathology, Mysore Medical College and Research Institute, Mysuru, Karnataka, India

Abstract
Background: Vermiform appendix, although a rudimentary structure in humans is one of the frequently
encountered specimens in the routine drill of a histopathologist. Acute appendicitis is the most rampant
diagnosis that frequently demands an emergency procedure. However, grossly normal- appearing
appendix, removed from patients with suspected acute appendicitis, on histopathological examination may
harbour a more serious underlying pathology. Therefore it is rationale to examine all the operated
specimens.
On the other hand literature shows that appendicitis can be associated with peripheral blood eosinophilia,
thereby necessitating complete hemogram, prior to preparation of the patient.
Aims and Objectives
1. To study the histomorphology of appendicitis specimens with special interest to unusual
$\quad$ presentations.
To correlate peripheral blood eosinophilic count in cases of subacute appendicitis.
Department of Histopathology MMC \&RI from K.R. hospital. A total of 125 cases were included in the
present study that were clinically suspected to be acute or recurrent appendicitis.
Results: In this descriptive study, the records pertaining to 125 appendicectomy specimens, at our tertiary
care centre were studied and compared with the available data.
Conclusion: It is of utmost importance to examine all the appendicectomy specimens so as to not miss on
any unusual or coexisting pathology.
Keywords: Appendicitis, Unusual presentation, Eosinophilia, Sub acute appendicitis.

\section{Introduction}

Vermiform appendix, although a rudimentary structure in humans is one of the frequently encountered specimens in the routine drill of a histopathologist. Acute appendicitis is the most rampant diagnosis that frequently demands an emergency procedure.
The incidence of appendicitis is increasing in India and other developing countries, mainly in urban cities due to increased acceptance towards western diet. ${ }^{[1,2]}$ In spite of all the recent advancements, clinical diagnosis of acute appendicitis is accurate in only $60-80 \%$ of cases. [1,3] A grossly normal appearing appendix, removed from patients with suspected acute or 
recurrent appendicitis, on histopathological examination may harbour a more serious underlying pathology. Therefore it is rationale to examine all the operated specimens.

Historically, the most popular theory regarding the pathogenesis of acute appendicitis has been that of obstruction of the appendiceal lumen. ${ }^{[4]}$ Some of the classical obstructive lesions frequently encountered include faecolith, lymphoid hyperplasia and foreign bodies. However, numerous unusual factors could involve the appendix, which comprise parasitic infestations like enterobiasis, ascariasis, bacterial infections like tuberculosis or tumors such as carcinoid, primary/secondary adenocarcinoma, lymphoma, gastrointestinal stromal tumor, granular cell tumors, PEComas, inflammatory fibroid polyps, schwannomas, leiomyoma's and inflammatory myofibroblastic tumour and these are morphologically similar to their counterparts found elsewhere. ${ }^{[5,6]}$

On the other hand, literature shows appendicitis to be associated with elevated leucocyte count, thereby necessitating complete hemogram, prior to preparation of the patient.

Eosinophilia is the presence of $>450$ eosinophil's per microliter of blood and is common in many settings besides parasitic infections. However, not many studies show correlation between peripheral blood eosinophilia and eosinophils in appendicitis. In our study, we have attempted to analyse the same, with special interest to unusual presentations in the appendix.

\section{Aims}

1. To study the histomorphology of appendicitis specimens with special interest to unusual presentations.

2. To correlate peripheral blood eosinophilic count in cases of subacute appendicitis.

\section{Materials and Methods}

The present study was carried out with appendicectomy specimens received to the Department of Histopathology, Mysore Medical
College and Research Institute from K.R. hospital. A total of 125 cases were included in our study that were clinically suspected to be acute or recurrent appendicitis.

Appendicectomies done as a part of colectomy or hysterectomies were excluded from the present study.

A complete hemogram of patients diagnosed as subacute appendicitis on histopathology, was reviewed and absolute eosinophil count (AEC) of $>450 \mathrm{cu} / \mathrm{mm}$ was considered as Eosinophilia.

\section{Results}

We studied a total of 125 appendicectomy specimens which included both emergency appendicectomies and incidental appendectomies. Among the 125 cases 79 patients were males and 46 patients were females and the male to female ratio was 1.71:1.

The commonest age group involved in our study was 21-40 yrs age group (53\%), followed by 0 20 years $(27.8 \%), 41-60$ years $(14.7 \%), 61-80$ $(3.4 \%)$ and more 80 years $(0.8 \%)$. The youngest patient was seven months and the oldest patient was 90 years old.

Out of 125 specimens, $112(89.6 \%)$ had features of various types of appendicitis, while $13(10.4 \%)$ harboured unusual findings. (Table 1)

The unusual findings encountered in our study are as shown in Table 2 .

Of the 10 cases of Subacute appendicitis six cases were associated with peripheral blood eosinophilia, AEC >450/cumm.

Table 1: Histologic findings of appendicectomy specimen

\begin{tabular}{|l|c|c|}
\hline Diagnosis & No of cases & $\%$ of cases \\
\hline Acute appendicitis & 39 & $31.2 \%$ \\
\hline Subacute appendicitis with & 10 & $08 \%$ \\
\hline $\begin{array}{l}\text { Acute appendicitis } \\
\text { periappendicitis }\end{array}$ & 06 & $4.8 \%$ \\
\hline Gangrenous appendicitis & 01 & $0.8 \%$ \\
\hline $\begin{array}{l}\text { Recurrent / Chronic } \\
\text { appendicitis }\end{array}$ & 54 & $43.2 \%$ \\
\hline Eosinophilic Appendicitis & 01 & $0.8 \%$ \\
\hline Appendicular Perforation & 01 & $0.8 \%$ \\
\hline UNUSUAL FINDING & 13 & $10.4 \%$ \\
\hline
\end{tabular}




\section{JMSCR Vol||07||Issue $\|10\|$ Page 324-330 ||October}

Table 2: Unusual findings in appendicular specimen

\begin{tabular}{|l|c|}
\hline Unusual findings & No of cases \\
\hline Granulomatous & 01 \\
\hline Fibrous obliterans & 06 \\
\hline Mucocele & 01 \\
\hline Mucosal Hyperplasia & 01 \\
\hline Leiomyoma & 01 \\
\hline Inflammatory myofibroblastic tumour & 01 \\
\hline Enterobiasis & 01 \\
\hline $\begin{array}{l}\text { Recurrent appendicitis with giant cell } \\
\text { reaction }\end{array}$ & 01 \\
\hline
\end{tabular}

Table 3: Comparison of histopathological findings

\begin{tabular}{|l|c|c|c|c|c|}
\hline Histopathological findings & Present study & Patel et al & $\begin{array}{c}\text { Chawda } \\
\text { HK et al }\end{array}$ & $\begin{array}{c}\text { Divya R et al } \\
(2016, \text { Aligarh, } \\
\text { India) }\end{array}$ & $\begin{array}{c}\text { Alun } \\
\text { Jones(2007, } \\
\text { England) }\end{array}$ \\
\hline Inflammatory lesions & $\mathbf{8 9 . 6 \% ( 1 1 2 )}$ & $\mathbf{9 1 . 3 \% ( 3 6 5 )}$ & $\mathbf{9 4 . 4 \%}$ & $\mathbf{9 2 . 3 \%}(\mathbf{3 0 0})$ & $\mathbf{7 7 \%}$ \\
\hline UNUSUAL FINDINGS & $\mathbf{1 0 . 4 \% ( 1 3 )}$ & $\mathbf{5 \% ( 2 0 )}$ & $\mathbf{4 . 6 \%}$ & $\mathbf{2 . 5 \%} \mathbf{( 0 8 )}$ & $\mathbf{3 . 7 5 \%}$ \\
\hline
\end{tabular}

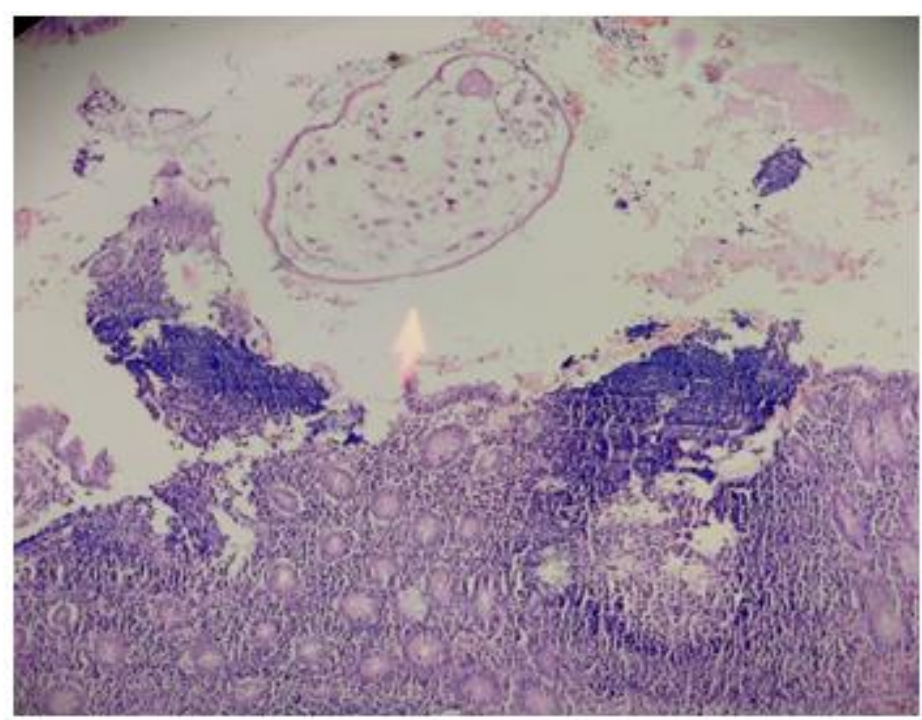

Fig 1: Enterobius Vermicularis: In the lumen of appendicitis case having a thick cuticle containing eggs inside. (H\&E,10X)

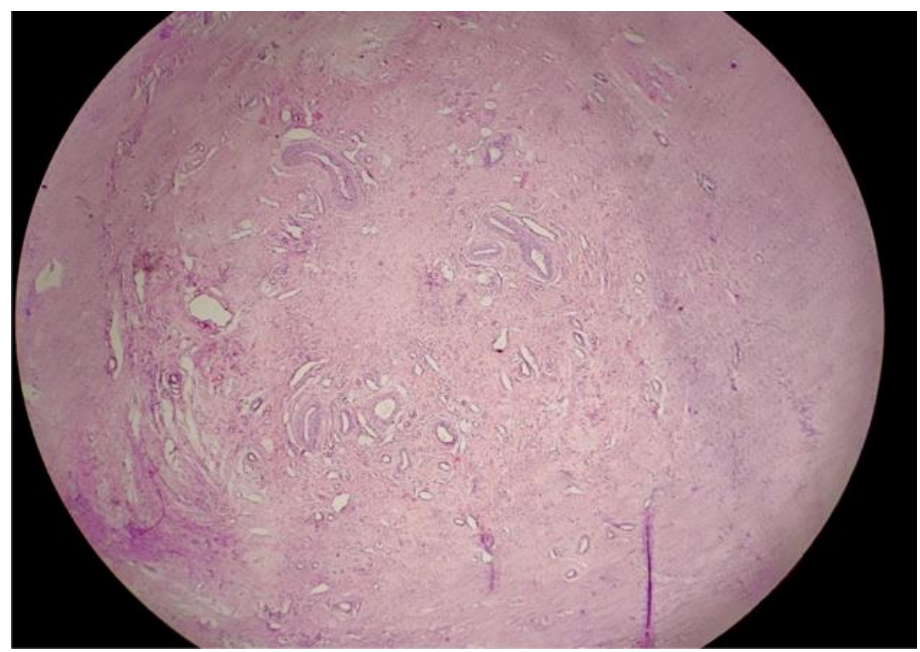

Fig 2: Fibrous obliterans of appendix - Lumen replaced by spindle cells in fibromyxoid background, loss of lymphoid follicles. (H \& E, 10X) 


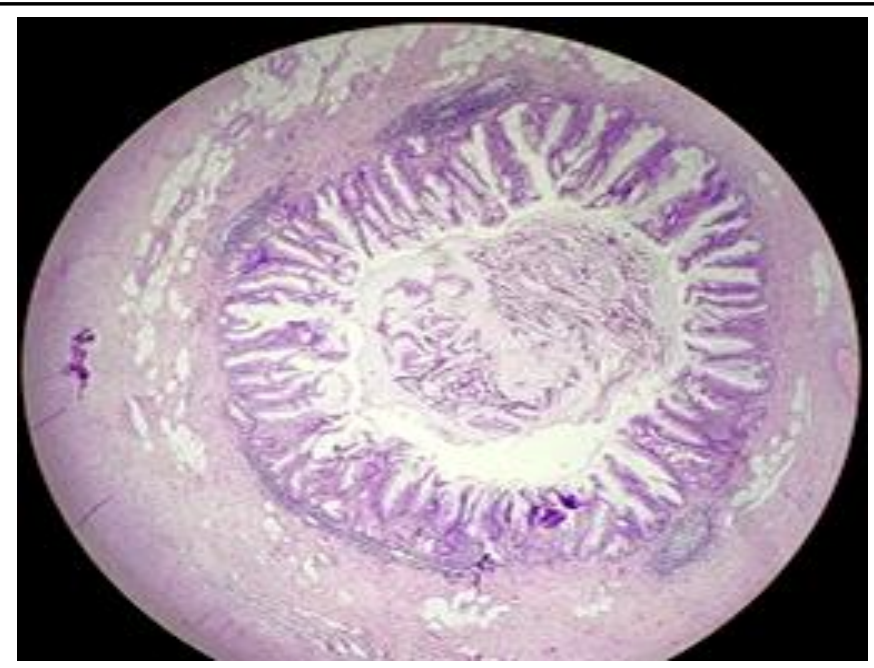

Fig 3: Mucosal Hyperplasia of Appendix -The lumen filled with mucinous material. Superficial portion shows a typical micropapillary configuration.(H\&E, 10X)

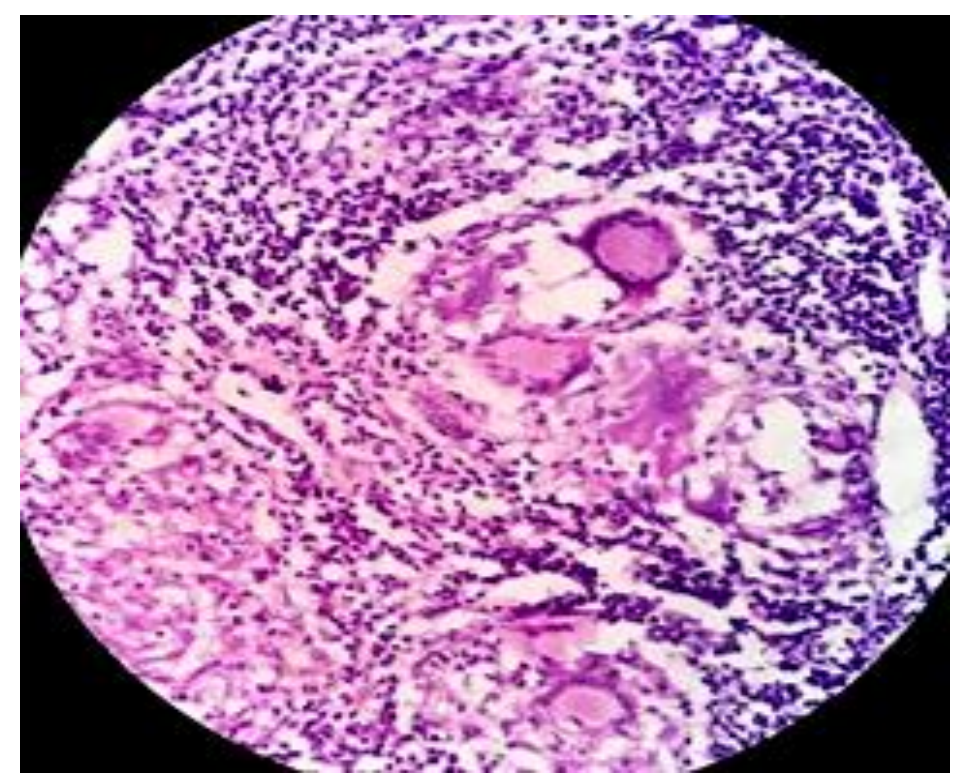

Fig 4: Granulomatous Appendicitis - Multinucleated langhans giant cells surrounded by epitheloid cells. (H\&E, 40X)

\section{Discussion}

Vermiform Appendix although considered as rudimentary structure in humans, ${ }^{[4]}$ harbours a wide variety of unusual inflammatory and neoplastic conditions presenting both as incidental findings and as causes of clinical signs and symptoms, that often mimic appendicitis. The knowledge about diseases of appendix including appendicitis, the most common disease, is far from complete. ${ }^{[12]}$ Therefore, it remains noteworthy for careful and systematic study both by the clinician and the pathologist.

The present study conducted among 125 appendicectomies, the age incidence of appendicitis was higher in 21-40 yrs age group (53\%), followed by $0-20$ years $(27.8 \%)$. Similar results were seen in study done by Patel et al and R. Sujatha et al.

In our study, maximum number of patients presenting with complaints of suspected appendicitis were males $(63.2 \%)$. Similar findings were observed in Chawda $\mathrm{HK}$ et al. (63.9\%) and R. Sujatha et al. (60.4\%) The male to female ratio in our study was found to be 1.71:1 which was similar to study conducted by $\mathrm{R}$. Sujatha et al.(1.5:1) and Patel et al (2.4:1).

Our study shows incidence of acute inflammation in appendix (31.2\%) to be less comparative to all 
other studies. Although similar results were found in study conducted by Chawda $\mathrm{HK}$ et al., the overall incidence of acute appendicitis was still higher than chronic appendicitis in their study as compared to the present study where Chronic inflammation accounted for $43.2 \%$.

Other in spectrum, constitute minority of proportion including sub acute, acute appendicitis with periappendicitis, gangrenous, eosinophilic appendicitis and one case of appendicular perforation.

As shown in Table 1, in our study unusual findings were found in 13 cases (10.4\%) of cases. In contrary study done by Patel et al and Chawda HK et al., found $5 \%$ and $4.6 \%$ unusual findings respectively.(Table 3)

Of the 13 cases, our study included 06 cases of fibrous obliterans of appendix. Only few literature have reported this entity. A case report done by I. R. Ilić et al., reported four cases of appendiceal neuroma presenting as acute appendicitis. [13] Obliteration of the tip of the appendix is a frequent finding, first described in 1928, consists of a variable mixture of nerve fibers, Schwann cells, neuroendocrine cells, fibrous tissue, and muscle, hence the variety of names for them including fibrous obliteration, neuroma, neuroappendicopathy, and neurogenic appendicitis. ${ }^{[4,13]}$ The association of appendiceal neuroma with clinical symptoms, such as abdominal pain, is unclear. Although it can sometimes mimic the acute/chronic appendicitis, the diagnosis of this entity can be found only after pathological examinations. ${ }^{[14,15]}$

Another important and rare incidental diagnosis in our study was Inflammatory Myofibroblastic tumour. R Vijayaraghavan et al. reported a case of Inflammatory Myofibroblastic tumour of appendix presenting as appendicitis. ${ }^{[6]}$ Considered as an aberrant or exaggerated response of the tissues to a chronic inflammatory process, IMFT could be a histological expression of an infective or reparatory process and, occasionally, a true neoplasm. ${ }^{[16]}$
In our study we also reported a rare case of appendiceal leiomyoma. There have been isolated reports of appendiceal leiomyoma and leiomyosarcoma. ${ }^{[4]}$

Our study also reported one case of Enterobius vermicularis associated with lymphoid hyperplasia $(0.8 \%)$. Study done by R Sujatha et al., reported the incidence to be $1.3 \%$. Enterobius vermicularis (also known as pinworms or oxyuriasis) is found in $0.6 \%-13 \%$ of otherwise normal appearing resected appendices. ${ }^{[4]}$

Another unusual incidental finding in our study was Mucosal Hyperplasia of the appendix.

A diffuse, non polypoid mucosal hyperplasia of the appendix has been described, sometimes in association with inflamed appendices, which can involve a large portion of the surface area of the mucosa, in contrast to hyperplastic polyps which tend to be localized. ${ }^{[4]}$

Other incidental finding was that of a Granulomatous appendicitis (0.8\%) which was similar to study done by Chawda $\mathrm{H} \mathrm{K}$ et al., $(0.71 \%)$. It can be caused by various infectious and noninfectious factors. Systemic conditions, such as Crohn's disease and sarcoidosis, may be associated with granulomatous inflammation of the appendix. However, infectious causes like Mycobacterium tuberculosis, Actinomyces spp etc... form a much more important cause in our country. ${ }^{[9,11]}$

We also reported a case of mucocele with a incidence of $0.8 \%$, similar to study done by Patel et al $(0.75 \%)$. The incidence of mucocele has been reported to range from $0.2 \%$ to $0.3 \%$ of all appendectomy specimens usually discovered as incidental findings at appendicectomy, or during laparotomy for another indication or at histological examination of an operative specimen. ${ }^{[9]}$ The definitive diagnosis of mucocele and its cause is possible only after histopathology. In the present study we also attempted to study the relation between Eosinophilia in peripheral blood and subacute appendicitis. And an interesting finding that we noticed was, in 10 cases that were diagnosed as subacute appendicitis, six cases 
$(60 \%)$ showed increase in eosinophils without an increase in total leucocyte count.

A study by Garza-Serna U et al., have described chronic appendicitis with an elevated count of eosinophils in the peripheral blood, without elevation of the expected white blood cell count, that can even present as an acute abdomen. ${ }^{[8]}$

The non - acute variants of appendicitis including recurrent, subacute and chronic appendicitis, are rarely diagnosed and remain subjects of case reports. ${ }^{[18]}$ In a review of appendectomies between 1924 and 1955, subacute appendicitis was the indication in one tenth of the cases. Recently, case reports have emerged demonstrating the persistence of non - acute variants of appendicitis as clinical entities. Subacute and Chronic appendicitis may occur due to partial obstruction of lumen with slower symptom progression. ${ }^{[18]}$

In a study conducted by G.C. Miller et al., showed eosinophilic inflammatory infiltrate in the appendix to be associated with a higher peripheral eosinophilia, which however did not reach the statistical significance. They also concluded that based on the laboratory and clinical parameters, the diagnosis of a separate entity subacute appendicitis cannot be made. ${ }^{[17]}$

Eosinophilia is common in many settings besides parasitic infections. Common causes include allergic reaction to drugs followed by allergies such as hay fever, asthma, eczema, serum sickness, allergic vasculitis and pemphigus. Eosinophilia is also seen in collagen vascular diseases and malignancies. $\left.{ }^{[7}\right]$ Since very sparse literature is available on the same, further studies are required to determine what the presence of eosinophils in appendix and peripheral blood eosinophilia represent.

\section{Conclusion}

In spite of advances in technology and imaging modalities, there is still a dilemma in the clinical diagnosis of appendicitis. Therefore it is of utmost importance to examine all the appendicectomy specimens so as to not miss any unusual or coexisting pathology that may affect subsequent clinical management of the patient. A complete blood count, though may not be very sensitive, still remains as the need of the hour with further studies required to show a correlation between peripheral blood eosinophilia and subacute appendicitis so as to narrow down the diagnosis and decide whether surgical intervention is warranted.

\section{Acknowledgements: Nil}

Sources of support in the form of grant: Nil.

\author{
Abbreviations \\ AEC - Absolute Eosinophil count \\ IMFT - Inflammatory Myofibroblastic tumor \\ PEComa's - Perivascular endotheloid cell \\ neoplasms \\ H\&E - Hematoxylin and Eosin
}

\section{References}

1. R. Sujatha et al. Histopathological spectrum of appendicectomy specimens A prospective study. Indian Journal of Pathology and Oncology, OctoberDecember 2017;4(4):638-642

2. Oguntola AS, Adeoti ML, Oyemolade TA. Appendicitis: Trends in incidence, age, sex and seasonal variations in South-western Nigeria. Ann Afr Med 2010;9:213-7.

3. Fergusson JAE, Hitos K, Simpson E. Utility of white cell count and ultrasound in the diagnosis of acute appendicitis. ANZ J Surg 2002;72:781-5.

4. Rosai, J., Ackerman, L. V., \& Rosai, J. Rosai and Ackerman's surgical pathology. Chapter 16: Edinburgh: Mosby; 2011.p.617-641

5. O'Connell PR. The vermiform appendix. In: Russell RC, Williams NS, Bulstrode CJ. editors. Bailey and Love's Short Practice of Surgery.26th ed. London: Arnold Hodder;2010.p.1203-18.

6. R Vijayaraghavan, R Chandrashekar, C S Belagavi. Inflammatory Myofibroblastic 
tumour of appendix. J Clin Pathol. 2006 Sep; 59(9): 999-1000

7. Patil SL, Patil LG, Masane PN, Agrawal PP. Eosinophilia: a case series with review on different clinical presentations of eosinophilia. Int J Adv Med 2015;2:312-6.

8. Garza-Serna U, Ramos-Mayo A,LopezGarnica D, Lopez-Morales J, DiazElizondo J, Flores-Villalba E (2016) Eosinophilic acute appendicitis and intraabdominal granuloma caused by Enterobius vermicularis in a pediatric patient. Surgical Infections Case Reports $1: 1, \quad 103-105, \quad$ DOI: 10.1089/crsi.2016.0029

9. Patel et al. Impact of Histopathological Examination of Appendix in Context to Clinical Management of Patients. Annals of Pathology and Laboratory Medicine, Vol. 4, Issue 6, November-December, 2017

10. Rabindranath D, Khan AA, Ansari H, Senthil P. Unusual incidental findings of routine histopathological examination of appendectomy specimens- a 2-year retrospective analysis with review of the literature. Int $\mathbf{J}$ of Allied Med Sci and Clin Res 2016; 4(1):90-98.

11. Jones AE, Philips AW, Jarvis JR, et al. The value of routine histopathological examination of appendicectomy specimens. BMC Surg 2007;10:7-17.

12. Chawda HK, Miskin AT, Dombale VD. Spectrum of histopathological lesion in surgically removed appendix, Journal of Drug Discovery and Therapeutics Available. 2015:3;53-56.

13. I. R. Ilić, N. M. Stojanović, P. J. Randjelović, et al., Four Cases of Appendiceal Neuroma Mimicking Acute Appendicitis. Facta Universitatis. Series: Medicine and Biology Vol. 17, No 2, 2015, pp. 60-62.
14. Schmutzer KJ, Bayar M, Zaki AE, Regan JF, Poletti JB. 331.-Tumors of the appendix. Dis Colon Rectum 1975; 18:324

15. Misdraji J, Graeme-Cook FM. Miscellaneous conditions of the 163.-appendix. Semin Diagn Pathol 2004; 21:151

16. Bonnet J P, Basset T, Dijoux D. Abdominal inflammatory myofibroblastic tumors in children: report of an appendiceal case and review of the literature. J Pediatr Surg 19963113111314.

17. Miller G, Wright R. Does subacute appendicits exist? Pathology. 2010;42:S72.

18. Berk D, Sylvester K. Subacute Appendicitis. Clinical Pediatrics. 2005;44(4):363-365. 